\title{
Endothelial cell expression of galectin-1 induced by prostate cancer cells inhibits T-cell transendothelial migration
}

\author{
Jiale He and Linda G Baum \\ Department of Pathology and Laboratory Medicine, UCLA School of Medicine, Los Angeles, CA, USA
}

\begin{abstract}
A critical control point in the immune response to tumors or to pathogens is the egress of lymphocytes from blood into damaged or infected tissue. While several specific endothelial cell proteins promote lymphocyte adhesion to and migration across endothelium, little is known about endothelial cell surface proteins that negatively regulate transendothelial migration of lymphocytes. Galectin-1 is a mammalian lectin expressed by a variety of cell types, including endothelial cells, that has pleiotropic anti-inflammatory effects. Galectin-1 is known to alter T-cell cytokine production and to trigger T-cell death. We now demonstrate that galectin-1 inhibits T-cell migration across endothelial cells, identifying a novel anti-inflammatory effect of galectin-1. We observed reduced T-cell migration across endothelial cells induced to increase galectin-1 expression by exposure to prostate cancer cell conditioned medium, compared to T-cell migration across control-treated endothelial cells, and the inhibitory effect of galectin-1 on T-cell migration was reversed by specific antiserum. Decreased T-cell migration was not due to decreased adhesion to galectin-1 expressing endothelial cells, nor to death of T cells, as T cells lacking core 2 O-glycans and thus resistant to galectin-1 death displayed reduced migration across endothelial cells. Galectin-1 on the surface of extracellular matrix also reduced the ability of $T$ cells to migrate through the matrix. $T$ cells bound to galectin-1-coated matrix demonstrated enhanced clustering of CD43, including at the T-cell:matrix interface, compared to CD43 on T cells bound to matrix in the absence of galectin-1. As translocation of CD43 to the trailing edge is essential for polarized T-cell migration, these data indicate that galectin-1-mediated clustering of CD43 contributes to the inhibitory effect on T-cell migration. Inhibition of T-cell migration is a novel anti-inflammatory activity of galectin-1.
\end{abstract}

Laboratory Investigation (2006) 86, 578-590. doi:10.1038/labinvest.3700420; published online 10 April 2006

Keywords: cell trafficking; endothelial cells; galectin-1; glycosylation; prostate cancer; T cells

Recruitment of peripheral blood lymphocytes to sites of tumors, infection, or tissue injury is a critical step in inflammation. ${ }^{1-4}$ Many factors regulate the type and extent of lymphocyte infiltration into inflamed tissue. These factors include the ability of lymphocytes to adhere to activated endothelium in inflamed tissue, to traverse the endothelial cell layer to enter tissues, to migrate through tissue, and to survive in the inflammatory milieu. Positive regulators of lymphocyte adhesion and migration, such as selectins, integrins, and VCAM, have been well characterized. However, little is known about endothelial cell surface molecules that negatively regulate lymphocyte migration across the endothelial barrier.

Correspondence: Dr LG Baum, MD, PhD, Department of Pathology and Laboratory Medicine, UCLA School of Medicine, 10833 LeConte Avenue, Los Angeles, CA 90095, USA.

E-mail: lbaum@mednet.ucla.edu

Received 15 December 2005; revised 28 February 2006; accepted 02 March 2006; published online 10 April 2006
Galectin-1 is a mammalian lectin that regulates T-lymphocyte survival and function. Galectin-1 is expressed on the surface of activated endothelium, stromal fibroblasts, tumor cells, and antigen presenting cells, with increased expression in inflamed and neoplastic tissues. ${ }^{5-14}$ Galectin-1 promotes survival of naive $\mathrm{T}$ cells, but induces apoptosis of activated T cells. ${ }^{6,15,16}$ Activated T cells also increase endogenous galectin-1 expression, ${ }^{17,18}$ suggesting that autocrine cell death may contribute to downregulation of a T-cell immune response. Administration of galectin-1 in autoimmune and transplant disease models suppresses T-cell-mediated inflammation, both by directly inducing T-cell apoptosis and by reducing interferon- $\gamma$, IL-2, and TNF- $\alpha$ production. $^{6,19}$ Galectin-1 also promotes T-cell production of IL-10 that can suppress Th1 responses. ${ }^{20}$ Increased galectin-1 expression by tumors and tumor-associated stroma was associated with decreased T-cell infiltration and decreased T-cell survival, whereas reduced galectin-1 expression by tumor cells results in enhanced T-cell-mediated 
tumor destruction. ${ }^{11-13,21}$ Similarly, decreased galectin-1 expression in synovial tissues of arthritis patients was associated with increased accumulation of inflammatory cells. ${ }^{10}$ Thus, galectin-1 has been proposed to downregulate T-cell-mediated inflammation. ${ }^{6}$

As mentioned above, galectin-1 expression on the surface of endothelial cells is increased by endothelial cell activation in vitro with LPS or cytokines, and increased galectin-1 expression by endothelial cells has been observed in inflamed human lymph nodes. ${ }^{22}$ Moreover, conditioned media (CM) from ovarian and prostate carcinoma cells increased galectin-1 expression by stromal cells and endothelial cells, although the mechanism by which this occurs is unknown. ${ }^{13,23}$ While the ability of endothelial cell galectin-1 to kill $\mathrm{T}$ cells has been demonstrated, ${ }^{16}$ little is known about the ability of endothelial cell galectin-1 to regulate other T-cell functions such as adhesion to endothelial cells and transendothelial migration. Using cancer cell CM to induce endogenous galectin-1 expression and secretion by endothelial cells, we have examined the effects of galectin-1 on T-cell-endothelial cell interactions. While galectin-1 expression did not affect T-cell adhesion to endothelium, we observed decreased transendothelial migration of $\mathrm{T}$ cells when galectin-1 expression on endothelial cells was increased, and similarly found that galectin-1 reduced T-cell migration through extracellular matrix. Thus, in addition to effects on T-cell function and survival, we propose a novel anti-inflammatory effect for galectin- 1 by reducing T-cell migration into sites of inflammation.

\section{Materials and methods}

\section{Chemicals and Reagents}

Recombinant human galectin-1 was prepared as previously described. ${ }^{24}$ Before use, galectin-1 was dialyzed in $8 \mathrm{mM}$ dithiothreitol (DTT) in PBS (10 $\mathrm{mM} \mathrm{NaPO}_{4}, 140 \mathrm{mM} \mathrm{NaCl}, \mathrm{pH}$ 7.4). The following antibodies were used: biotinylated rabbit antihuman galectin-1 Ig prepared in our laboratory as previously described; ${ }^{11}$ goat anti-rabbit Ig-horseradish peroxidase (HRP), goat anti-rabbit Ig-FITC from Jackson ImmunoResearch Laboratories Inc. (West Grove, PA, USA); anti-CD43-FITC (clone S7) from BD Biosciences (Bedford, MA, USA).

Reagents were purchased from the indicated suppliers: annexin V/propidium iodide (PI) from R\&D Systems (Minneapolis, MN, USA); DTT from Fisher Scientific (Fairlawn, NJ, USA); PBS, $O-$ phenylenediamine dihydrochloride and BSA from Sigma (St Louis, MO, USA); Enhanced ChemiLuminescence (ECL) kit and Ficoll-Paque from Pharmacia LKB Biotechnology (Piscataway, NJ, USA); 5,6carboxyfluorescein diacetate succinimidyl ester (CFSE) from Molecular Probes (Eugene, OR, USA); Matrigel and BioCoat Matrigel Invasion chamber
$(8 \mu \mathrm{m})$ from BD Biosciences; cell culture inserts $(0.4 \mu \mathrm{m})$ for galectin-1 secretion assay from Falcon/ Becton Dickinson (Franklin Lakes, NJ, USA); DiffQuick staining solution from Dade Behring (Newark, DE, USA); benzyl- $\alpha-N$-acetylgalactosamine (benzyl$\alpha$-GalNac) from CalBiochem (La Jolla, CA, USA); Zeocin from Invitrogen (Carlsbad, CA, USA); 96-well enhanced protein-binding enzyme linked immunosorbent assay (ELISA) plates (Immulon 2) from Thermo Labsystem (Franklin, MA, USA).

\section{Cell Culture}

BW5147 and $\operatorname{Phar}^{\mathrm{R}} 2.1$ cell lines were gifts of Dr Michael Pierce, University of Georgia. DU145 and LNCaP cells were obtained from American Type Culture Collection (Manassas, VA, USA). $\operatorname{Phar}^{\mathrm{R}} 2.1$, BW5147, LNCaP and DU145 cells were maintained in complete DMEM (Life Technologies Inc., Rockville, MD, USA) supplemented with $10 \%$ heatinactivated FBS (Hyclone, Logan, UT, USA), $2 \mathrm{mM}$ L-glutamine, $1 \mathrm{mM}$ MEM sodium pyruvate solution (Sigma Chemical Co., St Louis, MO, USA). BW5147 cells expressing core $2 \mathrm{~N}$-acetylglucosaminyltransferase $(\mathrm{C} 2 \mathrm{GnT})^{25}$ were grown in the same media containing $500 \mu \mathrm{g} / \mathrm{ml}$ zeocin. Human umbilical vein endothelial cells (HUVECs) were obtained from Cambrex Corp. (East Rutherford, NJ, USA) and maintained in EGM-2 BulletKit media (Cambrex). All cells were grown at $37^{\circ} \mathrm{C}$ in a $5 \% \quad \mathrm{CO}_{2}$ humidified atmosphere. CM were obtained from preconfluent DU145 prostate cancer cells after $48 \mathrm{~h}$ culture in serum-free DMEM as previously described. ${ }^{23}$ For experiments using CM, HUVECs were grown to $90 \%$ confluency, and media replaced by either prostate cancer cell CM or control DMEM, both supplemented with $2 \%$ FBS, in a 2:1 ratio of EBM-2 as previously described. ${ }^{23}$

\section{Immunoblot}

HUVECs, $1 \times 10^{6}$, were lysed in Tris-HCl $(50 \mathrm{mM}$, $\mathrm{pH}$ 7.4) containing $1 \%$ NP-40, $5 \mathrm{mM}$ EDTA, $150 \mathrm{mM} \mathrm{NaCl}, 1 \mathrm{mM}$ phenylmethyl sulfonyl fluoride, $10 \mu \mathrm{g} / \mathrm{ml}$ aprotinin, $10 \mu \mathrm{g} / \mathrm{ml}$ leupeptin (Sigma). Cell extracts were centrifuged at 13000 r.p.m. for $10 \mathrm{~min}$ and supernatants collected. Total protein concentration was determined with the Bio-Rad protein assay (Bio-Rad Laboratories Inc., Hercules, CA, USA). Immunoblotting was performed essentially as described, ${ }^{11}$ with the following modifications. Samples ( $20 \mu \mathrm{g}$ protein per lane) were loaded on a $15 \%$ SDS gel with 1 ng galectin- 1 as a positive control. After electrophoresis, samples were transferred to ECL Hybond nitrocellulose membrane. Membranes were incubated overnight in 5\% Trisbuffered saline containing $5 \%(\mathrm{w} / \mathrm{v})$ nonfat dried milk, $0.5 \%$ Tween $20(\mathrm{v} / \mathrm{v})$ before addition of rabbit polyclonal antiserum to galectin-1 (1:2000) for $1 \mathrm{~h}$, followed by washing and incubation with goat 
anti-rabbit IgG-HRP (1:2000) for $1 \mathrm{~h}$. After washing, proteins were detected by ECL. Assays were performed in quadruplicate and protein intensity quantified with a ChemiImager 5500 digital imaging system (Alpha Innotech Corp., San Leandro, CA, USA).

\section{ELISA Assay for Galectin-1}

To quantify galectin-1 secreted by cells into media, purified rabbit anti-galectin-1 IgG was diluted in $1 \times$ PBS to $10 \mu \mathrm{g} / \mathrm{ml}$, and $100 \mu \mathrm{l} /$ well used to coat a 96-well enhanced protein-binding ELISA plate (Immulon 2) overnight at $4^{\circ} \mathrm{C}$. Wells were washed three times with wash buffer $(1 \times$ PBS, $0.05 \%$ Tween 20) and blocked with 1\% BSA for $1 \mathrm{~h}$ at room temperature. After blocking, dilutions of recombinant human galectin-1 or CM were added to the wells for $1 \mathrm{~h}$ at room temperature. The wells were washed three times to remove unbound galectin-1. Biotinylated anti-galectin-1 IgG $(10 \mu \mathrm{g} / \mathrm{ml}$ in $10 \%$ blocking buffer) was added for $1 \mathrm{~h}$, and wells washed three times with wash buffer. Streptavidin-HRP 1:500 in blocking buffer) was added at room temperature for $30 \mathrm{~min}$. After washing, $200 \mu \mathrm{l}$ of $0.4 \mathrm{mg} / \mathrm{ml} o$-phenylenediamine dihydrochloride was added to each well, and absorbance of each well read at $490 \mathrm{~nm}$ using an automated microplate reader (Bio-Rad, Model 550). OD values were converted to protein concentration based on a recombinant human galectin-1 standard curve. ELISA quantification of cell surface galectin-1 was performed as previously described. ${ }^{11,22}$ To quantify galectin-1 secreted into Matrigel, HUVECs, DU145, or LNCaP cells were grown to $90 \%$ confluency in $0.4 \mu \mathrm{m}$ cell culture inserts with Matrigel in lower chamber for $48 \mathrm{~h}$. Inserts were removed and galectin-1 quantified by ELISA exactly as previously described. ${ }^{11}$ To detect galectin-1 in Matrigel by immunohistochemistry, the inserts were incubated with purified anti-galectin-1 $\operatorname{IgG~(1:100)~for~} 1 \mathrm{~h}$ at room temperature, washed, and bound antibody detected by goat anti-rabbit Ig-HRP (1:200) followed by 3-amino-9-ethylcarbazol.

\section{Cell Surface Galectin-1 Immunofluorescence}

HUVECs grown on coverslips were fixed with $2 \%$ paraformaldehyde at $4^{\circ} \mathrm{C}$ for $30 \mathrm{~min}$. After quenching with glycine and rinsing with $\mathrm{PBS}$, coverslips were blocked with $10 \%$ goat serum. Fixed cells were incubated with galectin-1 antiserum or normal rabbit serum as control, diluted in 1:2000 in PBS with $2 \%$ goat serum. After washing, bound antibody was detected with FITC-conjugated goat anti-rabbit Ig for $1 \mathrm{~h}$ in the dark at $20^{\circ} \mathrm{C}$. After washing, coverslips were mounted onto slides with $25 \mu$ l Prolong Anti-fade mounting medium (Molecular Probes, Eugene, OR, USA) and examined on an Axioskop 2 plus fluorescent microscope (Carl Zeiss MicroImaging Inc., Thornwood, NY, USA).

\section{Transendothelial Migration Assay}

Analysis of transendothelial migration was performed as previously described ${ }^{26}$ with the following modifications. HUVECs were seeded on a six-well transwell membrane insert ( $8 \mu \mathrm{m}$ pores) and maintained in EBM-2. When the monolayer of cells reached 90\% confluency, EBM-2 was replaced with experimental media (CM or control medium:EBM-2 at $2: 1$ ratio) and cells cultured for $24 \mathrm{~h}$ at $37^{\circ} \mathrm{C}, 5 \%$ $\mathrm{CO}_{2} .1 \times 10^{6} \mathrm{~T}$ cells were cultured for $24 \mathrm{~h}$ in serumfree medium, then placed in the upper chamber containing HUVECs and allowed to migrate to the underside of the chamber insert for $24 \mathrm{~h}$ at $37^{\circ} \mathrm{C}$, with experimental medium in the lower chamber. After $24 \mathrm{~h}$, nonmigratory cells from the upper surface of the membrane were removed by scrubbing with a cotton swab. Cells that migrated to the bottom surface of the insert were stained with Diff-Quick staining solution and quantified. The number of migrated cells was determined by counting five nonoverlapping random fields (100-500 cells total) on each chamber, and four to five chambers were counted for each experimental point.

To inhibit elongation of $O$-glycans, $\mathrm{T}$ cells were cultured for $72 \mathrm{~h}$ with $2 \mathrm{mM}$ benzyl- $\alpha$-GalNAc in $0.2 \%$ DMSO/DMEM, or in $0.2 \%$ DMSO/DMEM alone as a control. The $\mathrm{T}$ cells were added to endothelial cell monolayers and transendothelial migration determined as described above.

For antibody inhibition experiments, rabbit polyclonal anti-galectin-1 antiserum (diluted 1:500 in media) was added to endothelial monolayers before the addition of $\mathrm{T}$ cells. In these experiments, T-cell migration was assessed at $14 \mathrm{~h}$.

\section{Adhesion Assays}

HUVECs were grown to confluence on coverslips in EBM. Immediately before experiments, T cells were gently resuspended in $2 \mathrm{ml}$ prewarmed $\left(37^{\circ} \mathrm{C}\right) \mathrm{PBS}$ containing $10 \mu \mathrm{M}$ CFSE for $15 \mathrm{~min}$ in the dark. CFSElabeled T cells, $2 \times 10^{5}$, were added to the endothelial cell monolayer. T cells were allowed to adhere for $1 \mathrm{~h}$ at $37^{\circ} \mathrm{C}$. Nonadherent cells were removed by washing and the samples were fixed with $4 \%$ paraformaldehyde. Cells labeled with CFSE were examined on an Axioskop 2 plus fluorescent microscope at $\times 100$. The number of adherent cells was determined by counting five nonoverlapping random fields on each coverslip (400-500 cells total) and four to five coverslips were counted for each experimental point.

\section{Cell Death Analysis}

For cell death assays, HUVECs were seeded on coverslips and maintained in EBM-2 in six-well plates until reaching $80 \%$ confluence. EBM-2 was replaced with experimental media (CM or control 
DMEM with EBM-2 at 2:1 ratio) and cells incubated for $24 \mathrm{~h}$ at $37^{\circ} \mathrm{C}, 5 \% \mathrm{CO}_{2}$. The next day, $4 \times 10^{5} \mathrm{~T}$ cells were added to HUVEC monolayers for $1 \mathrm{~h}$ at $37^{\circ} \mathrm{C}$. After washing to remove nonadherent cells, $\mathrm{T}$ cells were stained with annexin V-FITC in binding buffer $(10 \mathrm{mM}$ HEPES, pH 7.4, $150 \mathrm{mM} \mathrm{NaCl}$, $2.5 \mathrm{mM} \mathrm{CaCl}_{2}, 1 \mathrm{mM} \mathrm{MgCl}_{2}$ ) for $20 \mathrm{~min}$ in the dark, washed with PBS, fixed with $4 \%$ paraformaldehyde, and quenched with $0.2 \mathrm{M}$ glycine. Coverslips were mounted onto slides with $25 \mu \mathrm{l}$ Prolong Anti-fade mounting medium (Molecular Probes). Annexin VFITC labeled cells were detected at $\times 200$ using an inverted Axioskop 2 plus fluorescent microscope. Annexin V fluorescence intensity was analyzed and quantified by Image ProPlus software (MediaCybernetics, San Diego, CA, USA) on five nonoverlapping random fields on each coverslip and four coverslips were counted for each experimental point. To inhibit $O$-glycan elongation, cells were treated with benzyl- $\alpha$-GalNAc for $72 \mathrm{~h}$ before cell death assays, as described above.

\section{T-Cell Migration through Matrigel}

Cell migration assays were performed as previously described. ${ }^{27}$ Briefly, six-well Matrigel transwell migration chambers were rehydrated for $2 \mathrm{~h}$ at $37^{\circ} \mathrm{C}, 5 \% \mathrm{CO}_{2}$, before coating with indicated doses of galectin-1. T cells cultured for $24 \mathrm{~h}$ in serum-free media, $1 \times 10^{6}$, were placed in the upper chamber and allowed to migrate to the underside of the chamber insert for $24 \mathrm{~h}$ at $37^{\circ} \mathrm{C}$. The lower chambers contained media with $10 \%$ FBS as a chemoattractant. After $24 \mathrm{~h}$, nonmigratory cells were removed from the upper surface of the membrane by scrubbing with a cotton swab and the migratory cells present on the underside of the membrane were fixed and stained with Diff-Quick staining solution and counted as above. Cell counts were performed on five nonoverlapping random fields for each chamber and four chambers were counted for each experimental point, and the percentage of migratory cells was normalized to corresponding controls. For antibody inhibition experiments, rabbit anti-galectin-1 antiserum or normal rabbit serum as a control (diluted 1:50 in media) was added to galectin-1 coated Matrigel for $30 \mathrm{~min}$ at room temperature before the addition of T cells.

\section{CD43 Localization on Adherent T Cells}

Thin Gel preparations of Matrigel were prepared on glass coverslips according to the manufacturer's instructions. Recombinant human galectin-1 ( $30 \mu \mathrm{M}$ in $200 \mu \mathrm{l}$ ) was added to the gel surface at room temperature as previously described. ${ }^{11} \mathrm{~T}$ cells $\left(10^{6}\right)$ were allowed to adhere to Matrigel in the presence or absence of galectin-1 for $1 \mathrm{~h}$ before fixation and staining with anti-CD43-FITC antibody. Slides were visualized on a Fluoview laser scanning confocal microscope (Olympus America Inc., Melville, NY, USA), using the $\times 100$ objective. Images collected from 5 to 10 fields (approximately 100 cells) for each experimental point were analyzed using Metamorph software (Downingtown, PA, USA).

\section{Statistical Analysis}

Data were analyzed by student's $t$-test, one-way ANOVA analysis. Unless otherwise indicated, data are presented as mean \pm s.e.m.

\section{Results}

Endothelial Cell Surface Expression of Galectin-1 and Deposition of Galectin-1 into Extracellular Matrix is Increased by Cancer Cell-Conditioned Medium

Galectin-1 is expressed by human endothelial cells. In vivo, galectin-1 expression in endothelium is increased on endothelial cells in inflamed lymph nodes compared to nonstimulated lymph nodes, ${ }^{22}$ and in vitro, galectin-1 expression on HUVECs is increased by treatment with proinflammatory cytokines and by CM from prostate carcinoma cells. ${ }^{22,23}$ To examine the role of endothelial cell surface galectin-1 in lymphocyte-endothelial interactions, we wished to use a system that induced physiologic levels of galectin-1 expression on endothelial cells, rather than adding exogenous galectin-1 as previously described, ${ }^{9}$ so we used prostate cancer cell $\mathrm{CM}$ to upregulate galectin-1 expression.

Galectin-1 is made in the cytosol, and HUVEC activation increases both synthesis of galectin-1 and secretion of galectin-1 that binds back to the HUVEC cell surface. ${ }^{22}$ As endothelial cell surface localization of galectin-1 would be critical to mediate lymphocyte-endothelial interactions, we first asked if CM from cancer cells increased the amount of galectin-1 specifically on the endothelial cell surface. As shown in Figure 1a, HUVECs grown in CM from DU145 cells had increased total galectin-1 expression compared to HUVECs grown in control media. Moreover, we observed a substantial increase in cell surface galectin-1 on HUVECs grown in CM compared to control medium (Figure 1b). HUVECs grown in $\mathrm{CM}$ had approximately $50 \%$ more galectin1 on the cell surface compared to HUVECs grown in control media. Increased cell surface galectin-1 on CM-treated HUVECs was also demonstrated by immunofluorescence microscopy of nonpermeabilized cells (Figure 1c). As a control, we determined by immunoblotting that CM alone had no detectable galectin-1 (data not shown).

We have previously demonstrated that stromal cells that synthesize galectin-1 can secrete galectin-1 into extracellular matrix. ${ }^{11}$ To determine if endothelial cells stimulated to increase galectin-1 expression also secrete galectin-1 into extracellular matrix, 
a

\section{Control CM-DU145}

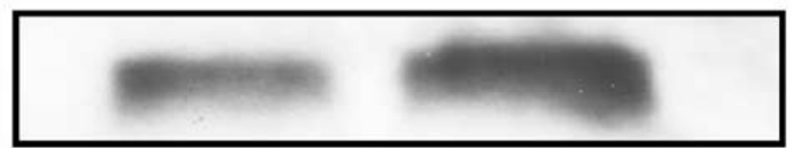

b
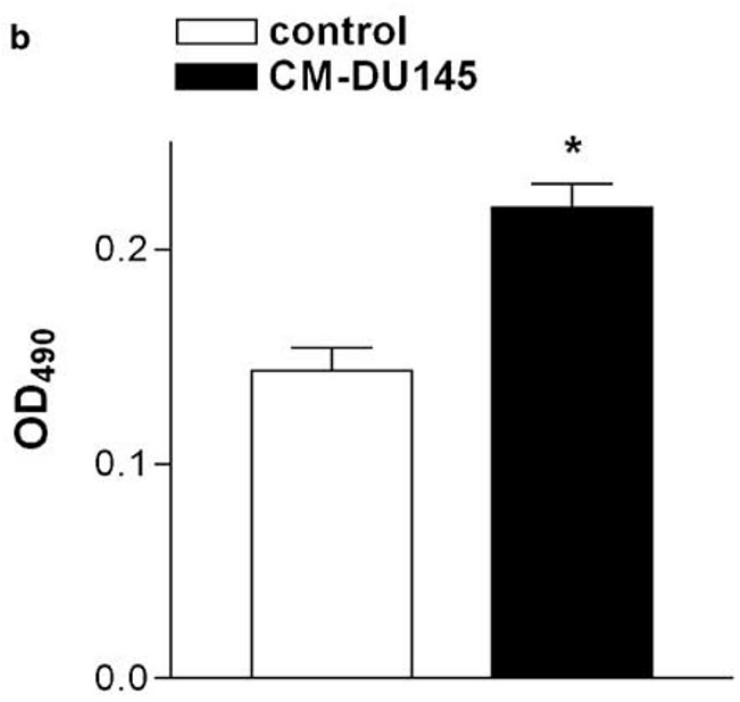

HUVEC cell surface galectin-1
C
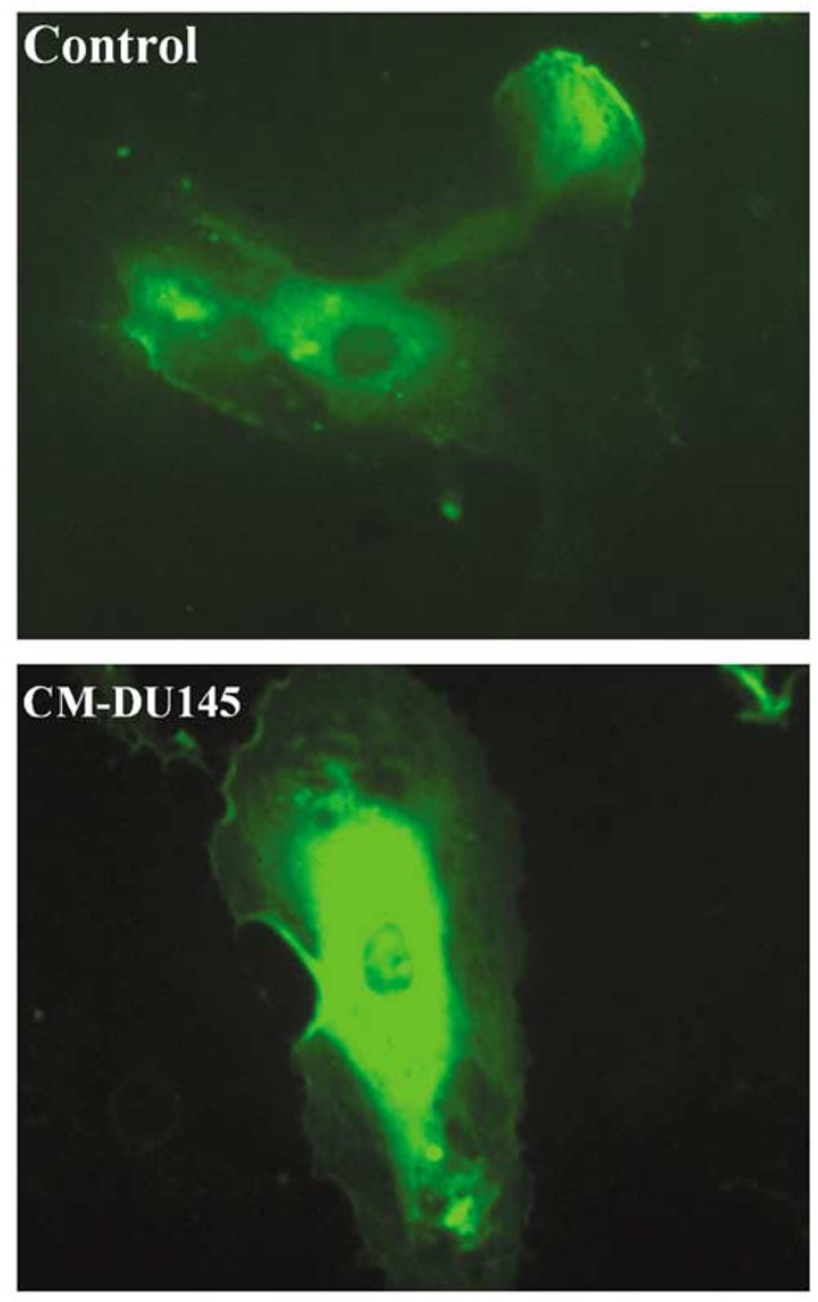

Figure 1 CM from DU145 prostate cancer cells (CM-DU145) increases HUVEC surface expression of galectin-1. (a) HUVECs were grown in control medium or CM for $24 \mathrm{~h}$. Galectin-1 expression in whole-cell extracts $(20 \mu \mathrm{g}$ total protein per lane) was examined by immunoblot. (b) HUVECs were grown in control medium or CM for $24 \mathrm{~h}$. Cell surface galectin-1 was detected by ELISA assay. ${ }^{*} P=0.0002$. (c) Fluorescence microscopy demonstrates increased cell surface galectin-1 on CM-treated HUVECS (lower panel) compared to control-treated HUVECs (upper panel) $(\times 400)$.

HUVECs were grown alone, or in chamber slides on porous membranes over solidified Matrigel; Matrigel is an extracellular matrix product containing laminin, collagen IV, entactin, nidogen, and heparan sulfate proteoglycans, but no galectin- $1 .{ }^{11}$ As shown in Figure 2, HUVECs grown in CM secreted more galectin-1 (Figure 2a) and deposited approximately threefold more galectin-1 onto Matrigel, compared to HUVECs grown in control medium (Figure 2b). Abundant galectin-1 was also detected by immunostaining throughout the Matrigel cultured with CM-treated HUVECs, while minimal galectin-1 was detected on Matrigel cultured with controltreated HUVECs (Figure 2c). In summary, stimulation of galectin-1 expression by HUVECs resulted in increased secretion of galectin-1, increased localization of galectin-1 onto the endothelial cell surface, and increased deposition of galectin-1 from endothelial cells into surrounding extracellular matrix.

\section{Galectin-1 Inhibits Transendothelial Migration of T Cells}

To examine the effects of increased endothelial cell surface galectin-1 on T-cell adhesion and transendothelial migration, we used a panel of T-cell lines that we have extensively characterized with regard to expression of galectin-1 counterreceptors, expression of glycosyltransferases that create galectin-1 ligands, and susceptibility to galectin-1-induced death. ${ }^{25}$ BW5147 cells (BW) express the galectin-1 receptors CD45 and CD43 and bind galectin-1, but do not express a specific glycosyltransferase, the $\mathrm{C} 2 \mathrm{GnT}$ that makes $O$-linked glycan ligands 

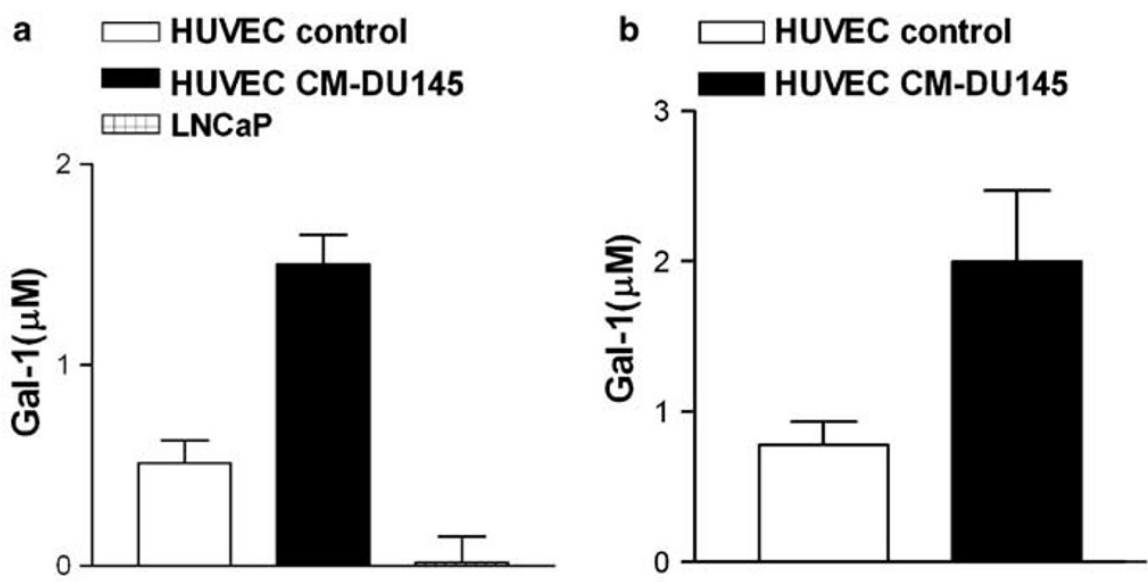

C
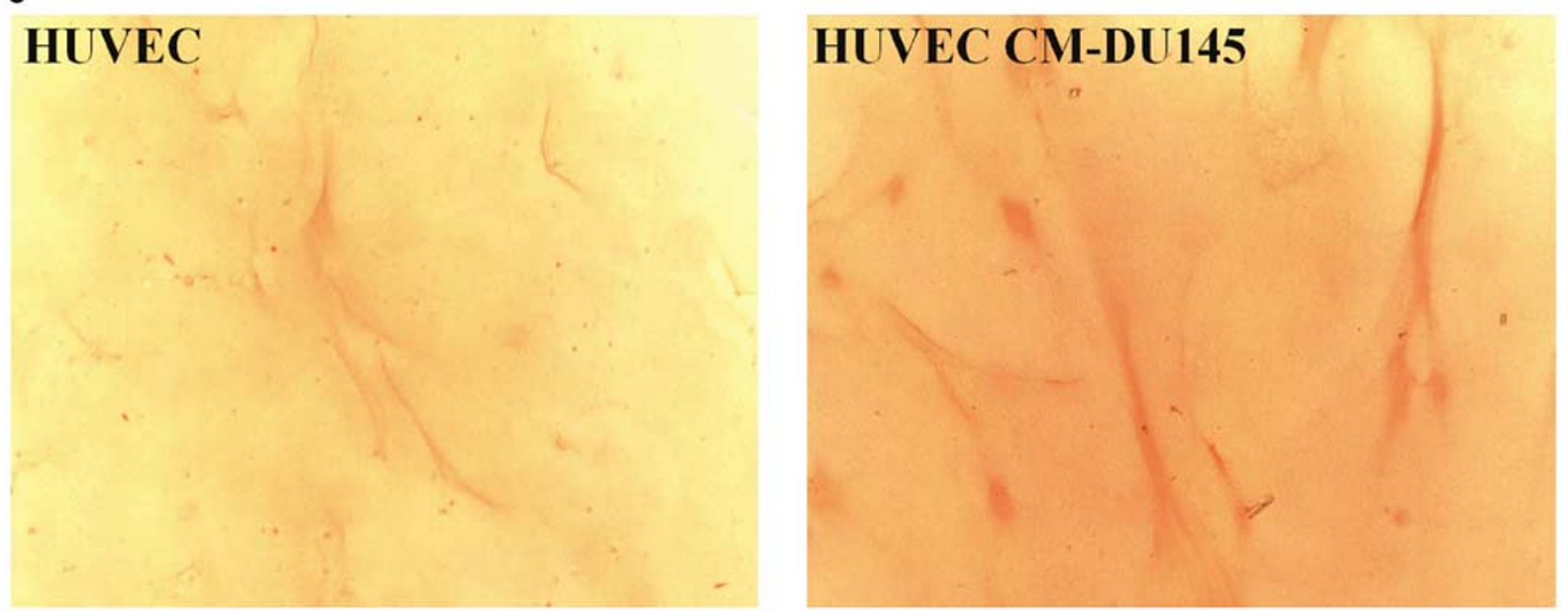

Figure 2 CM-DU145 increases HUVEC secretion of galectin-1. (a) Secretion of soluble galectin-1. Supernatants of CM-treated or controltreated HUVECs were collected and secreted galectin-1 quantified by ELISA. Supernatant from LNCaP cells that do not express galectin-1 was used as a negative control. (b) Secretion of galectin-1 into extracellular matrix. CM-treated or control-treated HUVECs were cultured in upper well inserts of chamber slides over solidified Matrigel in the bottom wells for $48 \mathrm{~h}$. Galectin-1 secreted onto the Matrigel was quantified by ELISA assay. (c) CM-treated or control-treated HUVECs were plated on solidified Matrigel for $48 \mathrm{~h}$ and galectin-1 on the Matrigel detected by immunohistochemistry (red) $(\times 400)$. No galectin-1 was detected in Matrigel in the absence of HUVECs (data not shown).

important for galectin-1-induced death. $\mathrm{Pha}^{\mathrm{R}} 2.1$ cells, derived from BW cells, express CD43, CD45, and $\mathrm{C} 2 \mathrm{GnT}$ and are susceptible to galectin-1induced death. BWC2GnT cells are BW cells stably transfected with cDNA encoding $\mathrm{C} 2 \mathrm{GnT}$, and are thus also susceptible to galectin-1-induced death (see Table 1).

As shown in Figure 3a and b, increased expression of galectin-1 on the surface of CM-treated HUVECs decreased the number of $\mathrm{T}$ cells that migrated across the HUVEC monolayer. While the total number of cells migrating across control treated HUVECs differed for the three cell lines, increased galectin-1 expression on HUVECs reduced migration of all three cell lines, regardless of the glycosyltransferases expressed by the cells. The reduction in T-cell trafficking across the endothelial cell monolayer in the presence of increased cell surface galectin-1 could result from effects on three
Table 1 Glycoprotein receptor, glycosyltransferase expression, and galectin-1 susceptibility ${ }^{\mathrm{a}}$

\begin{tabular}{|c|c|c|c|c|c|}
\hline T-cell line & $C D 43$ & $C D 45$ & $C 2 G n T$ & $G n T V$ & Gal-1 death \\
\hline BW5147 & + & + & _- & + & - \\
\hline $\mathrm{Pha}^{\mathrm{R}} 2.1$ & + & + & + & - & + \\
\hline BWC2GnT & + & + & + & + & + \\
\hline
\end{tabular}

${ }^{\mathrm{a}}$ Phenotypic information from Nguyen et $a l^{25}$ and Galvan et al. ${ }^{28}$

separate steps in this process: cell adhesion, cell death or cell migration. We evaluated each of these three possibilities. As shown in Figure 4a, adhesion of all three cell lines to the upper surface of the endothelial cell monolayer was equivalent in control-treated and CM-treated samples. Thus, increased expression of galectin-1 on the endothelial 
584
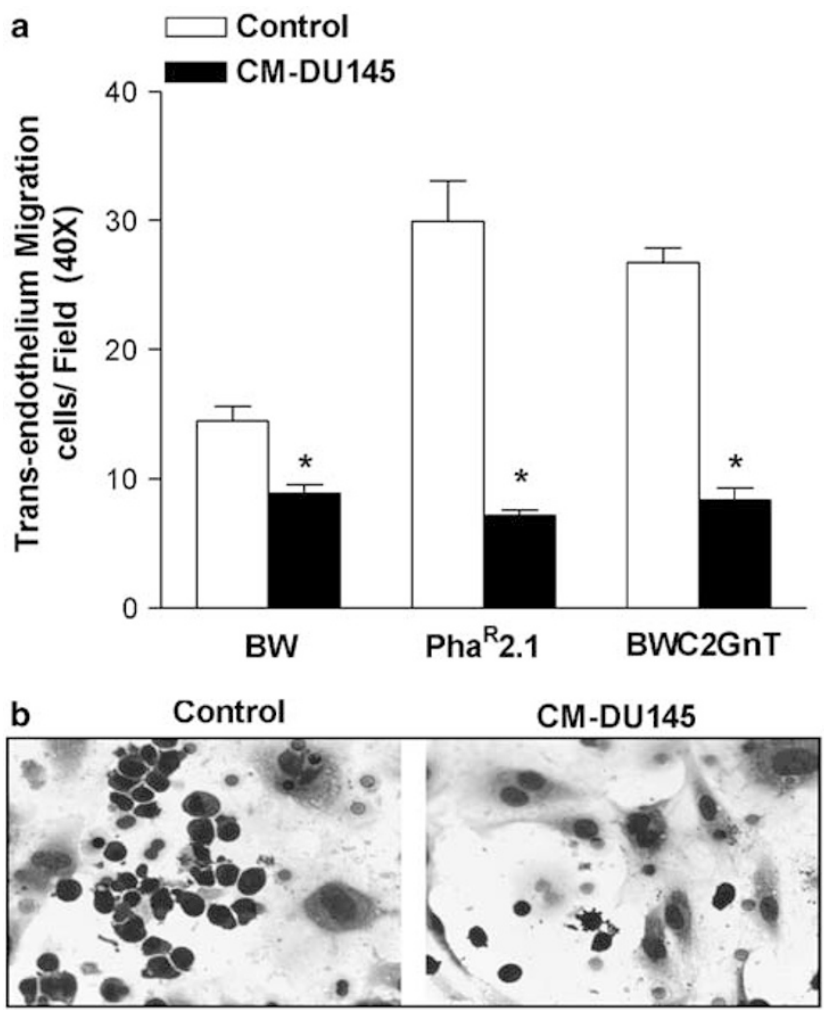

$\mathrm{Pha}^{\mathrm{R}} 2.1$

Figure 3 Reduced transendothelial migration of $\mathrm{T}$ cells on CMtreated HUVECs. (a) Confluent HUVECs in upper well inserts were cultured with control medium or CM-DU145 for $24 \mathrm{~h}$. T cells were added to the upper surface of HUVEC monolayers and allowed to migrate for $24 \mathrm{~h}$. Migrated cells on the underside of the inserts were stained and quantified as described in Materials and methods. One representative of three replicate experiments is shown. (b) $\mathrm{T}$ cells that migrated to the bottom surface of the membrane inserts are shown $(\times 400)$. ${ }^{*} P<0.003$ for BW cells and $P<0.0001$ for Phar $^{\mathrm{R}} 2.1$ and BWC2GnT cells.

cell surface did not affect adhesion of $\mathrm{T}$ cells to endothelial cells in this system.

As mentioned above, $\mathrm{Pha}^{\mathrm{R}} 2.1$ and BWC2GnT cells, but not BW cells, express $\mathrm{C} 2 \mathrm{GnT}$ that creates an $O$-linked saccharide ligand essential for galectin1 death of T cells. ${ }^{25}$ While we observed reduced transendothelial migration of BW cells that are resistant to galectin-1-induced death across CMtreated HUVECs (Figure 3a), the reduction in migration of $\mathrm{Pha}^{\mathrm{R}} 2.1$ and BWC2GnT cells was greater than that observed for BW cells. Thus, we reasoned that the reduced transendothelial migration of $\mathrm{Pha}^{\mathrm{R}} 2.1$ and BWC2GnT cells in Figure 3a could result at least in part from death of $\mathrm{T}$ cells bound to galectin-1 on CM-treated endothelial cells. We assessed death of the three T-cell lines on HUVECs. As shown in Figure 4b, BW cells did not die when bound to HUVECs, consistent with our prior observation that BW cells are resistant to galectin-1 death. ${ }^{25}$ A significant fraction of $\mathrm{Pha}^{\mathrm{R}} 2.1$ and BWC2GnT cells bound to CM-treated endothelial cells became annexin V-positive, compared to a

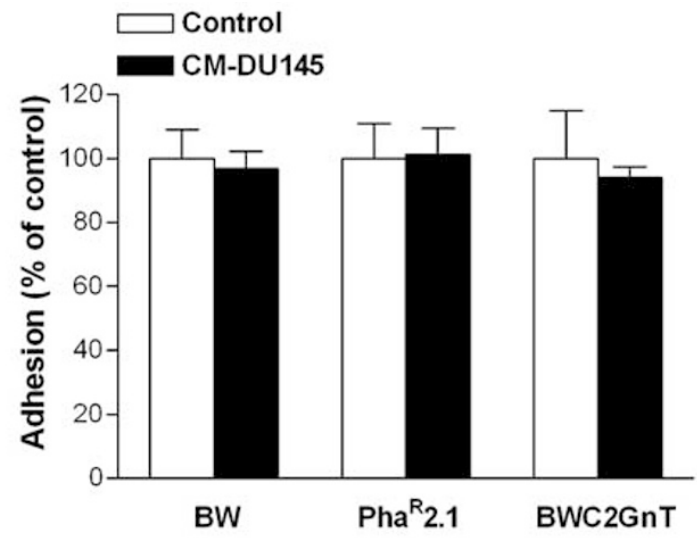

b
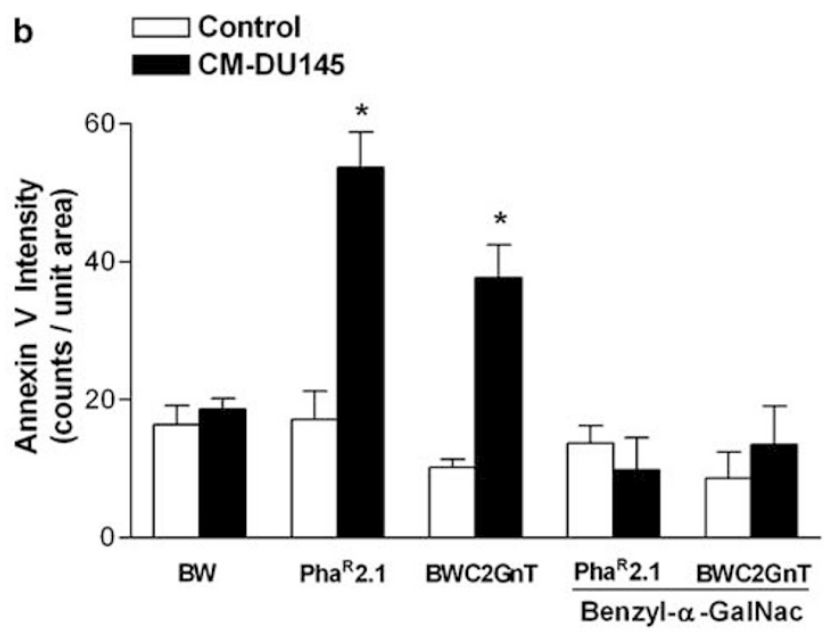

Figure 4 Effects of CM-treated HUVECs on T-cell adhesion and Tcell death. (a) Growth of HUVECs in CM-DU-145 does not alter Tcell adhesion. CFSE-labeled $\mathrm{T}$ cells were added to the upper surface of HUVEC monolayers and allowed to adhere for $1 \mathrm{~h}$ at $37^{\circ} \mathrm{C}$, and adherent cells quantified as described in Materials and methods. One representative of four replicate experiments is shown. (b) Death of susceptible T cells on CM-treated HUVECs. T cells were added to CM-treated or control-treated HUVEC monolayers. After $1 \mathrm{~h}$, cell death was detected by staining with annexin V-FITC. Annexin V-FITC intensity was analyzed and quantified as described in Materials and methods. BW cells did not die when bound to CM-treated HUVECs, while $\mathrm{Pha}^{\mathrm{R}} 2.1$ and BWC2GnT became annexin V-positive when bound to CM-treated HUVECs. Inhibition of $O$-glycan elongation with benzyl- $\alpha-\mathrm{Gal}-$ NAc abrogated death of $\mathrm{Pha}^{\mathrm{R}} 2.1$ and BWC2GnT cells. One representative of two replicate experiments is shown. ${ }^{*} P<0.002$.

$\mathrm{Pha}^{\mathrm{R}} 2.1$ and BWC2GnT cells bound to controltreated endothelial cells. However, death of $\mathrm{Pha}^{\mathrm{R}} 2.1$ and BWC2GnT cells on endothelial cells could be inhibited by pretreatment of the T cells with benzyl$\alpha$-GalNac. This glycosylation inhibitor blocks $O-$ glycan elongation and abrogates susceptibility of these T-cell lines to death induced by recombinant galectin- $1 .{ }^{25,28}$ Treatment of $\mathrm{Pha}^{\mathrm{R}} 2.1$ and BWC2GnT with benzyl- $\alpha$-GalNAc reduced T-cell death on galectin-1 expressing endothelial cells to background levels, comparable to that seen for BW cells, so that we could examine effects of galectin-1 on T-cell migration in the absence of cell death. 
As mentioned above, BW cells also demonstrated decreased transendothelial cell migration across CM-treated endothelial cells (Figure 3a) in the absence of cell death. To confirm that, in the absence of cell death, increased galectin-1 expression reduced transendothelial migration of $\mathrm{Pha}^{\mathrm{R}} 2.1$ and BWC2GnT cells T cells as well, we treated $\mathrm{Pha}^{\mathrm{R}} 2.1$ and BWC2GnT cells with benzyl- $\alpha$-GalNAc as in Figure 4b. As shown in Figure 5a, $\mathrm{Pha}^{\mathrm{R}} 2.1$ and BWC2GnT cells treated with benzyl- $\alpha$-GalNAc also demonstrated reduced migration across CM-treated HUVECs compared to control-treated HUVECs as we observed for BW cells. This demonstrated that increased expression of galectin-1 on the endothe-

a

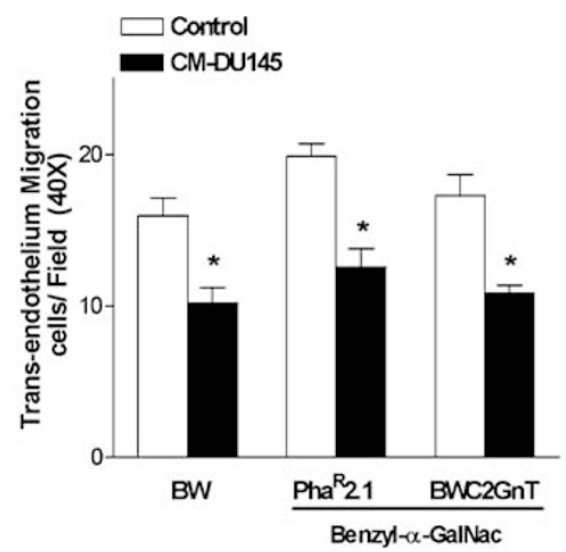

b
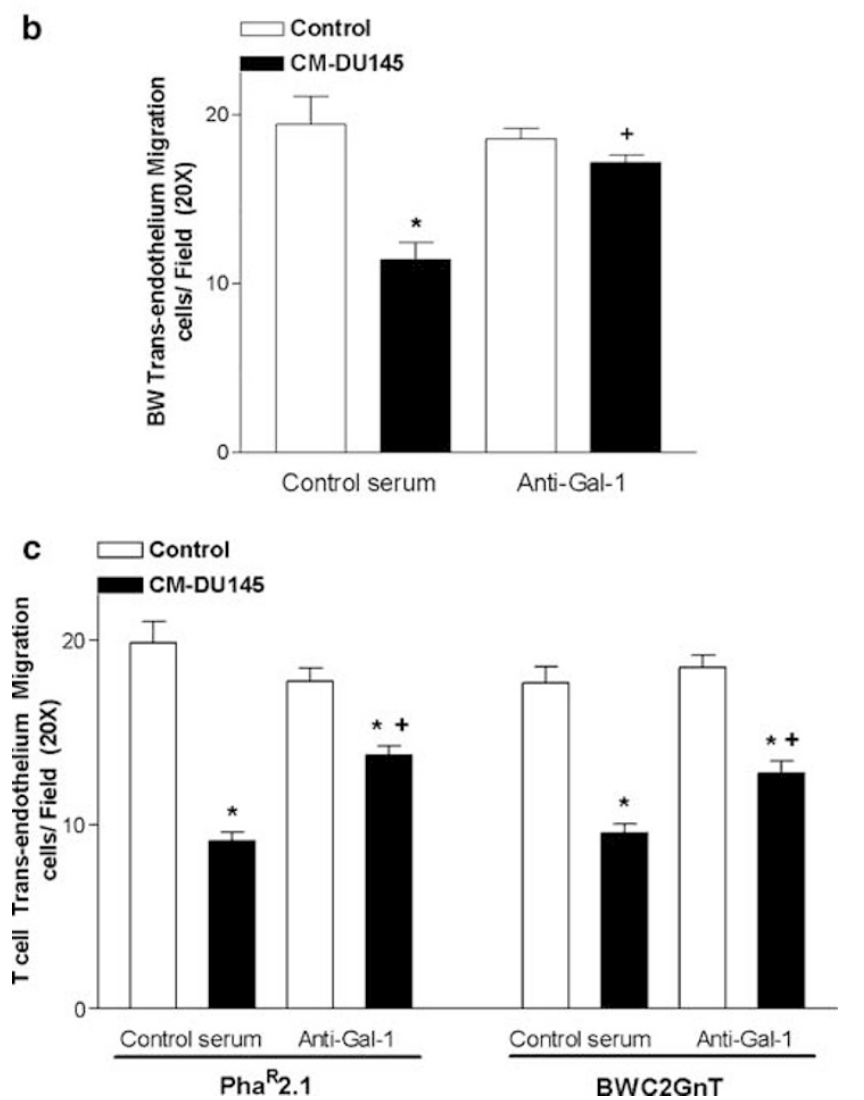

lial cell surface inhibited T-cell migration independently of any effect on T-cell death. To confirm that reduced transendothelial migration of $\mathrm{T}$ cells resulted from increased galectin-1 expression by the endothelial cells, anti-galectin-1 antiserum was added to the endothelial cell monolayers before the transendothelial T-cell migration assays (Figure 5b). The antiserum significantly reversed the inhibition of T-cell migration across CM-treated endothelial cells, but had no effect on T-cell migration across control-treated endothelial cells. Addition of control serum to CM-treated endothelial cells had no effect on the reduced T-cell migration across the endothelial cells.

We also confirmed that increased expression of galectin-1 contributed to the decreased transendothelial migration of $\mathrm{Pha}^{\mathrm{R}} 2.1$ and BWC2GnT cells, as shown in Figure 5a. Again, these two cell lines were pretreated with benzyl- $\alpha$-GalNAc to reduce core 2 O-glycan expression and make the cells resistant to galectin-1-induced death, to ensure that any reduction in transendothelial migration did not result from death of the cells. As shown in Figure 5c, addition of anti-galectin-1 antiserum to the endothelial cells reversed the reduction in transendothelial migration across CM-treated endothelial cells, compared to endothelial cells treated with control rabbit serum. In these experiments, the reversal of inhibition was not as complete as that seen for BW cells; this may be due to effects of the glycosylation inhibitor, or may indicate that additional molecules on CM-treated endothelial cells affect transendothelial migration of these T-cell lines.

Figure 5 Galectin-1 inhibits transendothelial migration of T cells. (a) Reduced transendothelial migration of T cells occurs in the absence of cell death. $\mathrm{Pha}^{\mathrm{R}} 2.1$ and BWC2GnT cells were pretreated with benzyl- $\alpha$-GalNac for $72 \mathrm{~h}$, and transendothelial migration determined as described in Materials and methods. BW cells, and $\mathrm{Pha}^{\mathrm{R}} 2.1$ and BWC2GnT cells treated with benzyl- $\alpha$ GalNac, demonstrated decreased migration across CM-treated HUVECS compared to control-treated HUVECS. The decrease in T-cell migration for $\mathrm{Pha}^{\mathrm{R}} 2.1$ and BWC2GnT cells treated with benzyl- $\alpha$-GalNac was comparable to that observed for BW cells that are resistant to galectin-1-induced death. One representative of three replicate experiments is shown. ${ }^{*} P<0.05$, for difference between control- and CM-treated HUVECs. (b) Reduced transendothelial migration across CM-treated HUVECs is reversed by addition of galectin-1-specific antiserum to the endothelial cells, but not by control rabbit serum. Transendothelial migration of BW cells across control and CM-treated HUVECs was determined as above, except that migration was determined $14 \mathrm{~h}$ after addition of $\mathrm{T}$ cells to HUVECs. Values are from duplicate samples in two replicate experiments $(n=4)$. ${ }^{*} P=0.001$ for difference between control- and CM-treated HUVECs. ${ }^{+} P=0.002$ for difference between control serum and anti-galectin-1 antiserum. (c) Reduced transendothelial migration of $\mathrm{Pha}^{\mathrm{R}} 2.1$ and $\mathrm{BWC} 2 \mathrm{GnT}$ cells, treated as in Figure 5a with benzyl- $\alpha$-GalNac to inhibit $O$-glycan elongation, is reversed by addition of anti-galectin-1 antiserum to the endothelial cells, but not by control rabbit antiserum. Transendothelial migration was assessed as described for Figure 5b. ${ }^{*} P=0.001$ for difference between control- and CM-treated HUVECs. ${ }^{+} P<0.02$ for difference between control serum and anti-galectin-1 antiserum. 
Galectin-1 Inhibits Migration of T Cells through Extracellular Matrix

To further assess the ability of galectin-1 to inhibit Tcell migration, we examined T-cell migration through Matrigel. As described above, Matrigel is a complex extracellular matrix material that does not contain galectin-1. ${ }^{11}$ As endothelial cells secrete galectin-1 into Matrigel (Figure 2), increased galectin-1 production by endothelial cells would result in increased galectin-1 on the cell surface as well as in the surrounding extracellular matrix.

As shown in Figure 6a, BW and $\mathrm{Pha}^{\mathrm{R}} 2.1$ cells migrated through a layer of Matrigel to the underside of the chamber insert, where the lower chamber contained $10 \%$ FBS as a chemoattractant. However, when galectin-1 was added to the upper surface of the Matrigel, galectin-1 caused a concentrationdependent reduction in migration of BW cells through Matrigel. We observed similar results for $\mathrm{Pha}^{\mathrm{R}} 2.1$ cells, with an even greater reduction in the number of $\mathrm{Pha}^{\mathrm{R}} 2.1$ cells accumulating on the underside of the chamber insert in the presence of galectin-1. To eliminate the component of cell death, $\mathrm{Pha}^{\mathrm{R}} 2.1$ cells were pretreated with benzyl- $\alpha$-GalNAc to block galectin-1-induced death, exactly as described above, and the effect of galectin-1 on cell migration through the Matrigel layer was assessed. $\mathrm{Pha}^{\mathrm{R}} 2.1$ cells treated with benzyl- $\alpha$-GalNAc still demonstrated reduced migration through galectin-1 coated Matrigel comparable to that observed for BW cells, again demonstrating that the inhibitory effect of galectin-1 on T-cell migration is independent of any effect on cell death.

To confirm that inhibition of T-cell migration through galectin-1 coated Matrigel was directly due to addition of galectin-1, BW cell migration through galectin-1 coated Matrigel was assessed in the presence of anti-galectin-1 antiserum or control rabbit serum. The concentration of galectin-1 that gave the greatest inhibition of migration, $9.4 \mu \mathrm{g} / \mathrm{cm}^{2}$ (Figure 6a) was used, and the galectin-1 coated Matrigel was treated with or without anti-galectin-1 antiserum or control rabbit serum, as shown in Figure 6c. Inhibition of BW cell migration was reversed by addition of anti-galectin-1 antiserum to the galectin-1 coated Matrigel, but not by normal rabbit serum. Neither anti-galectin antiserum nor normal rabbit serum in the absence of galectin-1 on the Matrigel had any effect on T-cell migration (Figure 6c). These data demonstrated that galectin-1 at the surface of the extracellular matrix directly blocked migration of $\mathrm{T}$ cells through matrix.

\section{Galectin-1 Inhibition of T-Cell Migration is Associated} with T-Cell Distribution of CD43

Galectin-1 binds oligosaccharide ligands on specific glycoprotein receptors on $\mathrm{T}$ cells, including CD43, CD45, and $\beta 1$ and $\beta 2$ integrins. ${ }^{29-31} \mathrm{~A}$ number of oligosaccharide ligands and glycoprotein receptors
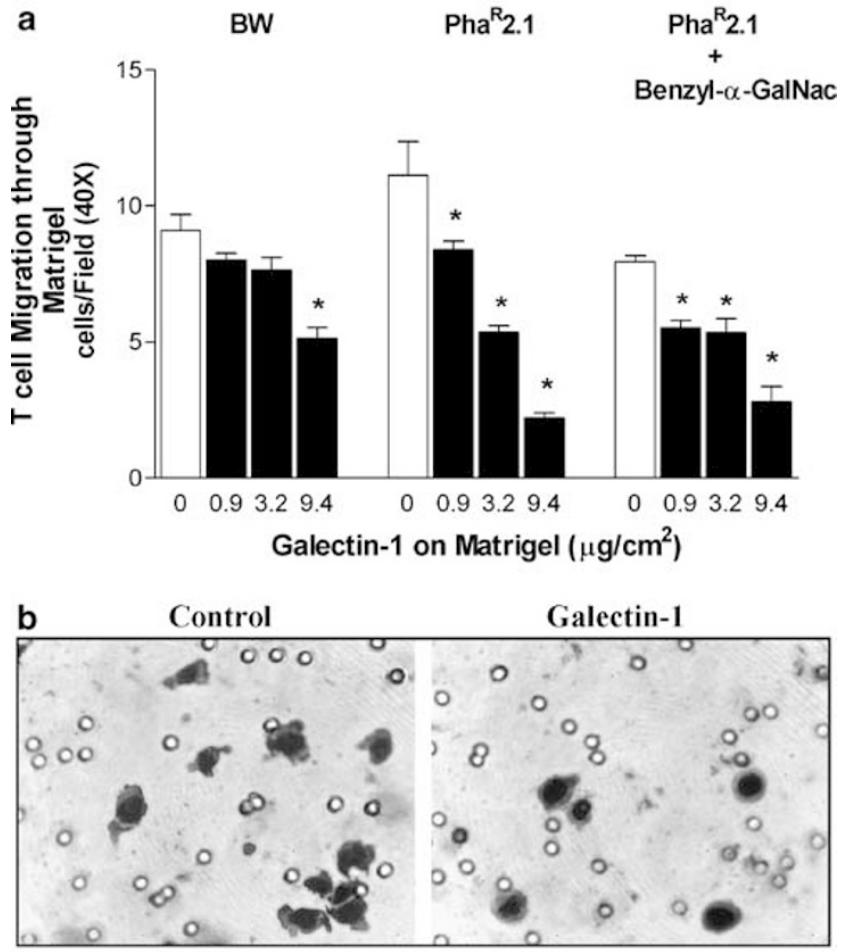

BW

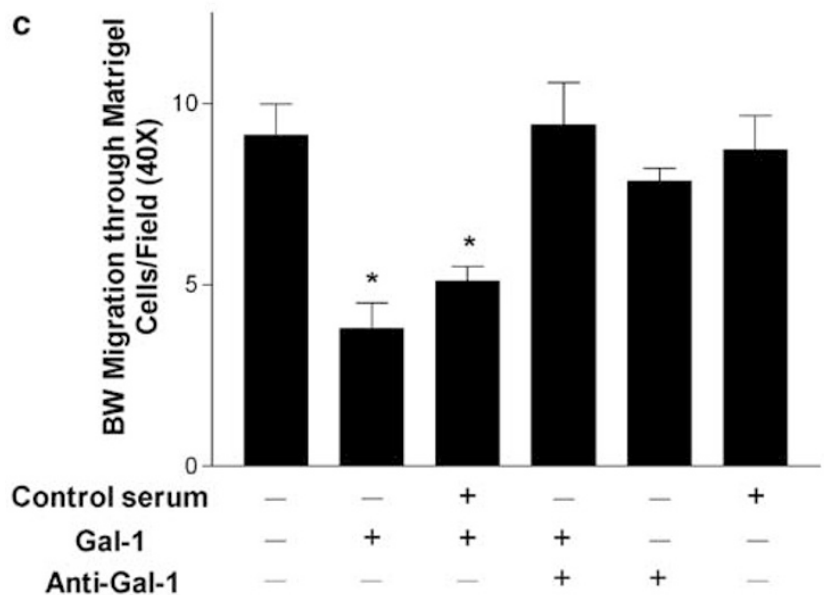

Figure 6 Galectin-1 inhibits T-cell migration through extracellular matrix. (a) Matrigel was coated with the indicated amount of galectin-1. T cells were added to the top surface of the Matrigel and allowed to migrate towards the lower surface for $24 \mathrm{~h}$. T-cell migration was determined as described in Materials and methods. BW cells that are resistant to galectin-1-induced cell death and Phar $^{R} 2.1$ cells treated with benzyl- $\alpha$-GalNAc demonstrated reduced migration through galectin-1-coated Matrigel compared to control Matrigel. ${ }^{*} \mathrm{P}<0.001$ for difference in migration compared to control (open column). (b) Migrated BW cells (dark) are visible on the underside of the Matrigel layer; clear circles are pores in the filter $(\times 400)$. (c) Matrigel was coated with galectin-1 (9.4 $\mu \mathrm{g} /$ $\mathrm{cm}^{2}$ ) or left uncoated and the effect of anti-galectin-1 antiserum on T-cell migration assessed. Addition of anti-galectin-1 antiserum, but not normal rabbit serum, to galectin-1 coated Matrigel $30 \mathrm{~min}$ before the addition of BW T cells abrogated the inhibitory effect of galectin-1 on BW cell migration through Matrigel, while neither anti-galectin-1 antiserum nor control rabbit serum alone had no effect in the absence of galectin-1. ${ }^{*} P<0.005$ for difference in migration compared to control sample (first column). 
on T cells could be involved in galectin-1-mediated inhibition of T-cell migration. Galectin-1 preferentially binds to lactosamine sequences that can be elongated on branched $N$ - or $O$-glycans. On $N$ glycans, these branched structures are typically made by the GnT V, an enzyme that modifies $N$ glycans on integrins. ${ }^{28}$ However, PhaR2.1 cells do not express the GnT V enzyme (Table 1). As PhaR2.1 cells also demonstrated decreased migration across endothelial cells and Matrigel in the presence of galectin-1 (Figures 3, and 4), we reasoned that the inhibitory effect of galectin-1 on T-cell migration was not likely due to interactions with GnT V modified $N$-glycans.

Galectin- 1 can also bind to $O$-glycans on T-cell glycoproteins. The T-cell surface mucin CD43 that is a receptor for galectin-1 contains over $80 \mathrm{O}$-linked glycans, ${ }^{29}$ and CD43 contributes about $50 \%$ of the total T-cell surface binding capacity for galectin-1 (Hernandez and Baum, unpublished observations). Importantly, CD43 localization on the cell surface differs between migrating and stationary $\mathrm{T}$ cells. CD43 localizes to the uropod of migrating $\mathrm{T}$ cells, and this localization step is critical for determining migrating T-cell polarity. ${ }^{32-34}$ We thus examined CD43 localization on $\mathrm{T}$ cells migrating through Matrigel in the presence or absence of galectin-1.

As shown in Figure 7a, BW cells adherent to Matrigel displayed uniform distribution of CD43 on the cell surface when examined in the XY plane. When the contact point between the $\mathrm{T}$ cell and Matrigel was examined in the XZ plane, there was also relatively uniform distribution of CD43. In contrast, when Matrigel was coated with galectin-1 before T-cell adhesion, CD43 on the T cells clustered into large patches on the membrane, observed in the XY plane (Figure 7a), as we have previously observed for $\mathrm{T}$ cells treated with soluble galectin-1.29 Importantly, when the contact site between the Tcell and galectin-1-coated Matrigel was examined, there was abundant CD43 clustered at the T-cell/ Matrigel interface (Figure 7a). The percent of T cells demonstrating CD43 clustering on control or galectin-1-coated Matrigel was quantified, and a significant increase in the percent of cells with clustered CD43 was observed for T cells bound to galectin-1coated Matrigel compared to Matrigel alone (Figure $7 b)$. These results indicated that galectin-1 on the Matrigel bound to CD43 on the adherent T cells and clustered CD43 at the Matrigel surface. As CD43 redistributes to the trailing edge of migrating $\mathrm{T}$ cells, ${ }^{32-34}$ these results suggest that one effect of galectin-1 at the T-cell/Matrigel interface may be to retard CD43 redistribution on migrating cells.

\section{Discussion}

Galectin-1 has pleiotropic effects on lymphocyte function, controlling cytokine production, cell survival, cell adhesion, and cell migration. ${ }^{6-9,35-37}$
Galectin-1 influences CD4 T-cell cytokine secretion, suppressing Type 1 and promoting Type 2 cytokine production. ${ }^{6,8,19,20}$ Galectin-1 can directly kill $\mathrm{T}$ lymphocytes and can augment T-cell death triggered by corticosteroids, TCR engagement and Fas ligation. ${ }^{16,35,36}$ While we have previously shown that galectin-1 expressed on the surface of endothelial cells kills adherent $\mathrm{T}$ cells, ${ }^{16}$ we now demonstrate that expression of galectin-1 on endothelial cells also inhibits transendothelial migration of $\mathrm{T}$ cells. While prior studies showed that galectin-1 on endothelial cells negatively regulates neutrophil transendothelial migration in vitro and neutrophil recruitment to the peritoneum in vivo, ${ }^{8}$ an inhibitory effect of galectin-1 on lymphocyte migration has not been described.

In this study, a fraction of $\mathrm{Pha}^{\mathrm{R}} 2.1$ and BWC2GnT cells that express core $2 \mathrm{O}$-glycans died when bound to galectin on endothelial cells or Matrigel (Figures $4,6)$. Core $2 \mathrm{O}$-glycans are highly expressed on the T-cell subsets that are susceptible to galectin-1 death, that is immature thymocytes and activated peripheral CD4 and CD8 T cells, ${ }^{38-40}$ and increased expression of core $2 \mathrm{O}$-glycans on T cells reduced Tcell infiltration into inflamed tissues. ${ }^{41}$ Thus, death of activated peripheral T cells on endothelial cells could occur at sites of inflammation and endothelial cell activation, as proinflammatory cytokines increase endothelial cell expression of galectin-1 and galectin-1-mediated T-cell death. ${ }^{16,22}$ Death of activated $\mathrm{T}$ cells could also occur on tumor-associated endothelium in prostate cancer, as prostate cancer cells secrete factors that stimulate galectin-1 production by endothelial cells, ${ }^{23}$ an effect that we found enhanced death of adherent $\mathrm{Pha}^{\mathrm{R}} 2.1$ and BWC2GnT cells (Figure 4). Multiple sites of galectin1 expression by endothelial cells, ${ }^{22,23}$ stromal cells ${ }^{11,12}$ and tumor cells ${ }^{21}$ may all contribute to the ability of tumors to kill infiltrating activated T cells.

Conversely, T-cell subsets that do not display core $2 \mathrm{O}$-glycans, for example naïve peripheral T cells, are not susceptible to galectin-1 death. ${ }^{15,16,25,28,40}$ In vivo, circulating $\mathrm{T}$ cells that leave the bloodstream to infiltrate inflamed tissue would include naïve $\mathrm{T}$ cells lacking core 2 O-glycans. However, our data indicate that galectin-1 could exert an antiinflammatory effect on naïve $\mathrm{T}$ cells as well by preventing transendothelial T-cell migration, as we observed for BW cells lacking C2GnT (Figures 3, 5, and 6). This effect may result from galectin-1 recognition of saccharide ligands on T-cell surface glycoproteins that are different from the core 2 $O$-glycans required for galectin-1-induced T-cell death. As protein-carbohydrate interactions are typically low affinity/high avidity interactions, ${ }^{42}$ lectins such as galectin-1 may have several preferred saccharide ligands presented on different glycoprotein or glycolipid backbones, with binding specificity provided by clustering of glycans to provide high avidity binding sites. In addition to core $2 O$-glycans, galectin-1 can bind to clustered 
a

Control
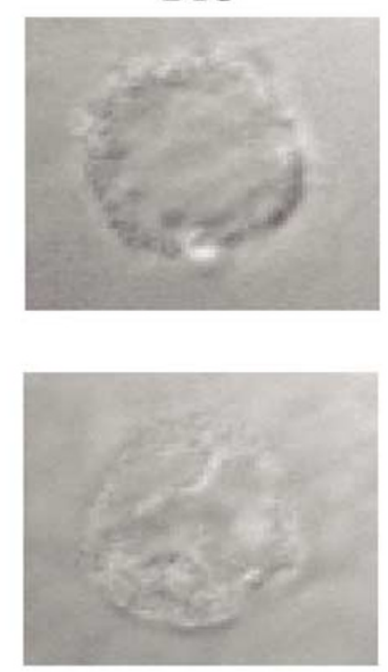

XY
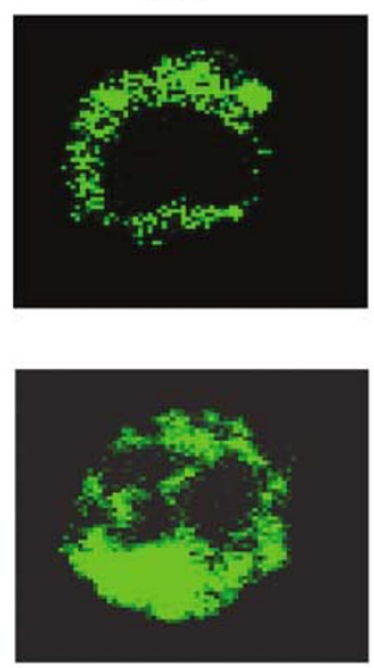
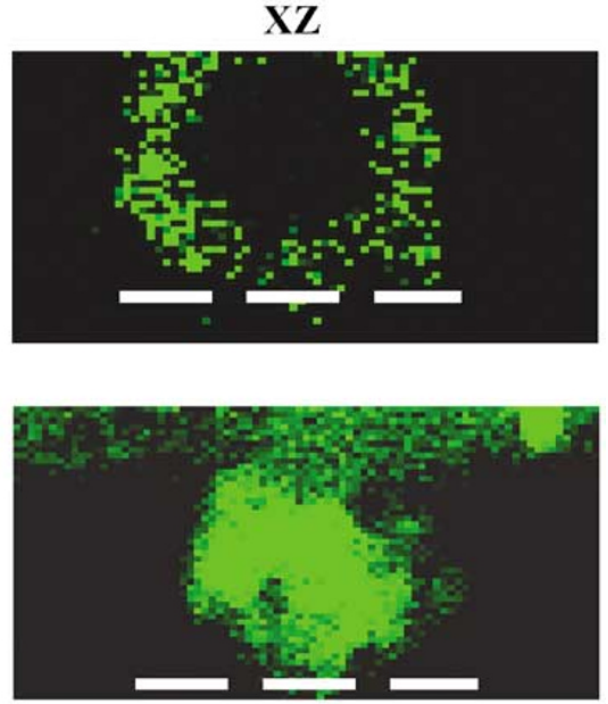

b

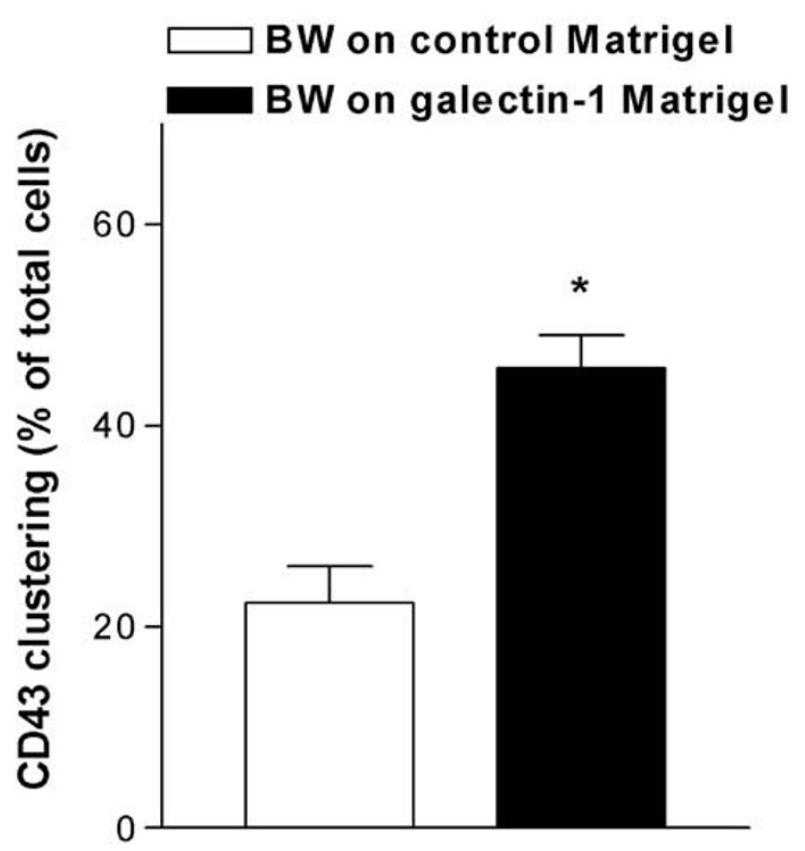

Figure 7 Galectin-1 inhibition of migration is associated with altered T-cell distribution of CD43. (a) Cell surface localization of CD43 on BW T cells adherent to control Matrigel or Matrigel coated with galectin-1, detected with anti-CD43-FITC. (left) DIC image of adherent T cell in XY plane. (center) Localization of CD43 detected by anti-CD43-FITC in the XY plane. In the absence of galectin-1 (Control), CD43 was diffusely distributed around the cell perimeter. On galectin-1 coated Matrigel, CD43 was clustered around the cell surface. (right) Localization of CD43 in the XZ plane. In the absence of galectin-1 (Control), minimal staining of CD43 was detected at the T-cell:Matrigel interface, depicted by dashed lines. On galectin-1 coated Matrigel, CD43 was clustered at the T-cell:Matrigel interface $(\times 1000)$. $(\mathbf{b})$ Quantification of BW cells with clustered CD43 on control Matrigel or galectin-1-coated Matrigel. Clustering was analyzed by confocal microscopy, and images were collected from 5 to 10 fields (approximately 100 cells) for each condition. ${ }^{*} P<0.05$.

core $1 O$-glycans on cell surface glycoproteins such as $\mathrm{CA}_{125^{43}}$ and CD43 (Hernandez and Baum, unpublished observations). Thus, galectin-1 can bind to different saccharide ligands on T-cell surface glycoproteins to regulate T-cell functions other than cell death.

Many of the cell surface glycoproteins that can bind galectin-1 regulate cell adhesion and migration, including CD43. CD43, that translocates to the trailing edge of migrating $\mathrm{T}$ cells, bears 80-90 $\mathrm{O}$ glycans; galectin-1 binding to CD43 is absolutely dependent on $O$-glycosylation, and galectin-1 can bind to core $1 O$-glycans on CD43 in the absence of core 2 O-glycan modifications (Hernandez and Baum, unpublished observations). Our observation that galectin-1-clustered CD43 at the T-cell/Matrigel interface suggests several mechanisms that could contribute to inhibition of T-cell migration by 
galectin-1. If galectin-1 on endothelial cells binds to and clusters CD43 at the T-cell-endothelial cell interface, this interaction may retard or prevent translocation of CD43 to the uropod, an effect proposed to enhance cell migration by removing steric constraints. ${ }^{44}$ Alternatively, galectin-1 binding to CD43 may have effects on the cytoskeleton, as CD43 movement to the uropod accompanies actin reorganization essential for T-cell migration ${ }^{32,33}$ and galectin-1 has been shown to block reorganization of the actin cytoskeleton. ${ }^{5,45}$ Finally, as CD43 associates with several intracellular kinases, galectin-1-induced clustering of CD43 may regulate intracellular signals that participate in cellular migration. ${ }^{46-48}$ Other glycoprotein receptors bearing $\mathrm{N}$ - or $\mathrm{O}$-glycans, such as integrins, ${ }^{30,32,49,50}$ may also participate in galectin-1-mediated interactions that regulate T-cell migration.

The results presented here demonstrate a novel anti-inflammatory activity for galectin-1. Previous work has shown that galectin-1 directly kills T cells, and also reduces T-cell production of proinflammatory cytokines such as interferon- $\gamma$. We now present evidence that galectin-1 also inhibits transendothelial migration of $\mathrm{T}$ cells in the absence of T-cell death. Thus, the reduced galectin-1 expression observed in inflamed tissues in rheumatoid arthritis patients may contribute to the T-cell infiltration and inflammatory damage in this disease.$^{10}$ Conversely, increased expression of galectin-1 by tumor-associated endothelium, as well as tumor stroma and tumor cells, may reduce T-cell infiltration into the tumor in addition to killing activated $\mathrm{T}$ cells that reach the tumor site. ${ }^{11-13,21,23}$ The activation state of the $\mathrm{T}$ cell, with concomitant changes in cell surface glycosylation, will likely determine which immunosuppressive effects of galectin-1 predominate in vivo, that is decreased T-cell infiltration, increased T-cell death, or both. Understanding the precise mechanisms that regulate these processes, including the T-cell saccharide ligands and glycoprotein receptors involved, will facilitate targeted application of the anti-inflammatory effects of galectin-1.

\section{Duality of interest}

None declared.

\section{Acknowledgements}

We thank Drs Karen Pace and Ken Dorshkind for critical reading of the manuscript, Dr Benhur Lee for assistance with Metamorph software, Mabel Pang for recombinant galectin-1, and Dr Michael Teitell and the members of the Baum lab for helpful discussions. This work was supported by NIH grant R01GM63281, Cancer Research Institute grant 01103591, and DOD grant DAMD 17-02-10022 to LGB.

\section{References}

1 Viswanathan K, Dhabhar FS. Stress-induced enhancement of leukocyte trafficking into sites of surgery or immune activation. Proc Natl Acad Sci USA 2005;102: 5808-5813.

2 Rao RM, Shaw SK, Kim M, et al. Emerging topics in the regulation of leukocyte transendothelial migration. Microcirculation 2005;12:83-89.

3 Montes de Oca P, Macotela Y, Nava G, et al. Prolactin stimulates integrin-mediated adhesion of circulating mononuclear cells to endothelial cells. Lab Invest 2005;85:633-642.

4 Ley K, Kansas GS. Selectins in T-cell recruitment to non-lymphoid tissues and sites of inflammation. Nat Rev Immunol 2004;4:325-335.

5 Rabinovich GA, Ariel A, Hershkoviz R, et al. Specific inhibition of T-cell adhesion to extracellular matrix and proinflammatory cytokine secretion by human recombinant galectin-1. Immunology 1999;97:100-106.

6 Rabinovich GA, Baum LG, Tinari N, et al. Galectins and their ligands: amplifiers, silencers or tuners of the inflammatory response? Trends Immunol 2002;23: 313-320.

7 Kuwabara I, Sano H, Liu FT. Functions of galectins in cell adhesion and chemotaxis. Methods Enzymol 2003;363:532-552.

8 Almkvist J, Karlsson A. Galectins as inflammatory mediators. Glycoconj J 1004;19:575-581.

9 La M, Cao TV, Cerchiaro G, et al. A novel biological activity for galectin-1: inhibition of leukocyte-endothelial cell interactions in experimental inflammation. Am J Pathol 2003;163:1505-1515.

10 Harjacek M, Diaz-Cano S, De Miguel M, et al. Expression of galectins-1 and -3 correlates with defective mononuclear cell apoptosis in patients with juvenile idiopathic arthritis. J Rheumatol 2001;28: 1914-1922.

11 He J, Baum LG. Presentation of galectin-1 by extracellular matrix triggers T cell death. J Biol Chem 2004; 279:4705-4712.

12 van den Brule FA, Waltregny D, Castronovo V. Increased expression of galectin-1 in carcinoma-associated stroma predicts poor outcome in prostate carcinoma patients. J Pathol 2001;193:80-87.

13 van den Brule F, Califice S, Garnier F, et al. Galectin-1 accumulation in the ovary carcinoma peritumoral stroma is induced by ovary carcinoma cells and affects both cancer cell proliferation and adhesion to laminin-1 and fibronectin. Lab Invest 2003;83:377-386.

14 Hernandez JD, Baum LG. Ah, sweet mystery of death; galectins and control of cell fate. Glycobiol 2002;12: 127R-136R.

15 Endharti AT, Zhou YW, Nakashima I, et al. Galectin-1 supports survival of naive $\mathrm{T}$ cells without promoting cell proliferation. Eur J Immunol 2005;35:86-97.

16 Perillo NL, Pace KE, Seilhamer JJ, et al. Apoptosis of $\mathrm{T}$ cells mediated by galectin-1. Nature 1995;378: 736-739.

17 Blaser C, Kaufmann M, Muller C, et al. Beta-galactoside-binding protein secreted by activated $\mathrm{T}$ cells inhibits antigen-induced proliferation of T cells. Eur J Immunol 1998;28:2311-2319.

18 Ouellet M, Mercier S, Pelletier I, et al. Galectin-1 acts as a soluble host factor that promotes HIV-1 infectivity through stabilization of virus attachment to host cells. J Immunol 2005;174:4120-4126. 
19 Baum LG, Blackall DP, Arias-Magallano S, et al. Amelioration of graft versus host disease by galectin1. Clin Immunol 203;109:295-307.

20 van der Leij J, van den Berg A, Blokzijl T, et al. Dimeric galectin-1 induces IL-10 production in T-lymphocytes: an important tool in the regulation of the immune response. J Pathol 2004;204:511-518.

21 Rubinstein N, Alvarez M, Zwirner NW, et al. Targeted inhibition of galectin-1 gene expression in tumor cells results in heightened $\mathrm{T}$ cell-mediated rejection; $\mathrm{A}$ potential mechanism of tumor-immune privilege. Cancer Cell 2004;5:241-251.

22 Baum LG, Seilhamer JJ, Pang M, et al. Synthesis of an endogeneous lectin, galectin-1, by human endothelial cells is up-regulated by endothelial cell activation. Glycoconj J 1995;12:63-68.

23 Clausse $\mathrm{N}$, van den Brule $\mathrm{F}$, Waltregny $\mathrm{D}$, et al. Galectin-1 expression in prostate tumor-associated capillary endothelial cells is increased by prostate carcinoma cells and modulates heterotypic cell-cell adhesion. Angiogenesis 1999;3:317-325.

24 Pace KE, Hahn HP, Baum LG. Preparation of recombinant human galectin-1 and use in T-cell death assays. Methods Enzymol 2003;363:499-518.

25 Nguyen JT, Evans DP, Galvan M, et al. CD45 modulates galectin-1-induced $\mathrm{T}$ cell death: regulation by expression of core 2 O-glycans. J Immunol 2001;167: 5697-5707.

$26 \mathrm{Li} \mathrm{Y,} \mathrm{Tondravi} \mathrm{M,} \mathrm{Liu} \mathrm{J,} \mathrm{et} \mathrm{al.} \mathrm{Cortactin} \mathrm{potentiates}$ bone metastasis of breast cancer cells. Cancer Res 2001;61:6906-6911.

27 Cho SY, Klemke RL. Extracellular-regulated kinase activation and CAS/Crk coupling regulate cell migration and suppress apoptosis during invasion of the extracellular matrix. J Cell Biol 2000;149: 223-236.

28 Galvan M, Tsuboi S, Fukuda M, et al. Expression of a specific glycosyltransferase enzyme regulates $\mathrm{T}$ cell death mediated by galectin-1. J Biol Chem 2000;275: 16730-16737.

29 Pace KE, Lee C, Stewart PL, et al. Restricted receptor segregation into membrane microdomains occurs on human T cells during apoptosis induced by galectin-1. J Immunol 1999;163:3801-3811.

30 Moiseeva EP, Williams B, Goodall AH, et al. Galectin-1 interacts with beta-1 subunit of integrin. Biochem Biophys Res Commu 2003;310:1010-1016.

31 Avni O, Pur Z, Yefenof E, et al. Complement receptor 3 of macrophages is associated with galectin-1-like protein. J Immunol 1998;160:6151-6158.

32 del Pozo MA, Cabanas C, Montoya MC, et al. ICAMs redistributed by chemokines to cellular uropods as a mechanism for recruitment of T lymphocytes. J Cell Biol 1997;137:493-508.

33 Serrador JM, Nieto M, Alonso-Lebrero JL, et al. CD43 interacts with moesin and ezrin and regulates its redistribution to the uropods of $\mathrm{T}$ lymphocytes at the cell-cell contacts. Blood 1998;91:4632-4644.

34 del Pozo MA, Nieto M, Serrador JM, et al. The two poles of the lymphocyte: specialized cell compartments for migration and recruitment. Cell Adhes Commun 1998;6:125-133.
35 Perillo NL, Uittenbogaart CH, Nguyen JT, et al. Galectin-1, an endogenous lectin produced by thymic epithelial cells, induces apoptosis of human thymocytes. J Exp Med 1997;185:1851-1858.

36 Matarrese P, Tinari A, Mormone E, et al. Galectin-1 sensitizes resting human T lymphocytes to Fas (CD95)mediated cell death via mitochondrial hyperpolarization, budding, and fission. J Biol Chem 2005;280: 6969-6985.

37 Dias-Baruffi M, Zhu H, Cho M, et al. Dimeric galectin-1 induces surface exposure of phosphatidylserine and phagocytic recognition of leukocytes without inducing apoptosis. J Biol Chem 2003;278:41282-41293.

38 Baum LG, Pang M, Perillo NL, et al. Human thymic epithelial cells express an endogenous lectin, galectin1 , which binds to core $2 \mathrm{O}$-glycans on thymocytes and T lymphoblastoid cells. J Exp Med 1995;181:877-887.

39 Jones A T, Federsppiel B, Ellies LG, et al. Characterization of the activation-associated isoform of CD43 on murine $\mathrm{T}$ lymphocytes. J Immunol 1994;153: 3426-3439.

40 Onami TM, Harrington LE, Williams MA, et al. Dynamic regulation of $\mathrm{T}$ cell immunity by CD43. J Immunol 2002;168:6022-6031.

41 Tsuboi S, Fukuda M. Overexpression of branched Olinked oligosaccharides on T cell surface glycoproteins impairs humoral immune responses in transgenic mice. J Biol Chem 1998;273:30680-30687.

42 Brewer CF, Miceli MC, Baum LG. Clusters, bundles, arrays and lattices: novel mechanisms for lectinsaccharide-mediated cellular interactions. Curr Opin Struct Biol 2002;12:616-623.

43 Seelenmeyer C, Wegehingel S, Lechner J, et al. The cancer antigen CA125 represents a novel counter receptor for galectin-1. J Cell Sci 2003;116:1305-1318.

44 Manjunath N, Correa M, Ardman M, et al. Negative regulation of T-cell adhesion and activation by CD43. Nature 1995;377:535-538.

45 Delbouck C, Doyen I, Belot N, et al. Galectin-1 is overexpressed in nasal polyps under budesonide and inhibits eosinophil migration. Lab Invest 2002;82: 147-157.

46 del Rio R, Rincon M, Layseca-Espinosa E, et al. PKCtheta is required for the activation of human $\mathrm{T}$ lymphocytes induced by CD43 engagement. Biochem Biophys Res Commun 2004;325:133-143.

47 Mattioli I, Dittrich-Breiholz O, Livingstone $\mathrm{M}$, et al. Comparative analysis of T-cell costimulation and CD43 activation reveals novel signaling pathways and target genes. Blood 2004;104:3302-3304.

48 Pedraza-Alva G, Merida LB, Burakoff SJ, et al. CD43specific activation of $\mathrm{T}$ cells induces association of CD43 to Fyn kinase. J Biol Chem 1996;271: 27564-27568.

49 Shaw SK, Ma S, Kim MB, et al. Coordinated redistribution of leukocyte LFA-1 and endothelial cell ICAM-1 accompany neutrophil transmigration. J Exp Med 2004;200:1571-1580.

50 Smith A, Carrasco YR, Stanley P, et al. A talindependent LFA-1 focal zone is formed by rapidly migrating $\mathrm{T}$ lymphocytes. J Cell Biol 2005;170: 141-151. 